\title{
"With This Disease, You Take Whatever Chances There Are"-A Study on Socio-Cultural and Psychological Aspects of Experiments Regarding Huntington's Disease
}

\author{
Susanne Lundin ${ }^{1,2}$, Eva Torkelson ${ }^{3}$, Marsanna Petersen ${ }^{1}$ \\ ${ }^{1}$ Department of Arts and Cultural Sciences, Lund University, Lund, Sweden \\ ${ }^{2}$ Stellenbosch Institute for Advanced Studies (STIAS), Wallenberg Research Centre at Stellenbosch University, Stellenbosch, South Africa \\ ${ }^{3}$ Department of Psychology, Lund University, Lund, Sweden \\ Email: susanne.lundin@kultur.lu.se,eva.torkelson@psy.lu.se,marsanna.petersen@kultur.lu.se
}

How to cite this paper: Lundin, S., Torkelson, E. and Petersen, M. (2016) "With This Disease, You Take Whatever Chances There Are"-A Study on Socio-Cultural and Psychological Aspects of Experiments Regarding Huntington's Disease. Open Journal of Medical Psychology, 5, 72-87. http://dx.doi.org/10.4236/ojmp.2016.54009

Received: September 2, 2016

Accepted: October 10, 2016

Published: October 13, 2016

Copyright $\odot 2016$ by authors and Scientific Research Publishing Inc. This work is licensed under the Creative Commons Attribution International License (CC BY 4.0).

http://creativecommons.org/licenses/by/4.0/

\begin{abstract}
Although relatively rare, Huntington's disease (HD) has fatal consequences. There is no cure for the disease, which leads to an early death. Worldwide, scientists are trying to develop therapeutic methods that could cure the disease, including new molecular gene therapeutic methods. At Lund University, research on HD is now about to step from animal models to trials with humans. The project is special in its design since it involves both medical studies and socio-cultural and psychological research to explore and meet the many challenges that experimental trials with HD patients give rise to. The aim of the present study was to investigate the viewpoints of individuals affected by HD on the issues of participation and exerting influence if taking part in a medical study on gene therapy that has not previously been tested on humans. A total of 16 participants, recruited through the national association for $\mathrm{HD}$ and through the neurological clinic at Lund University in Sweden, took part in a focus group or in a survey study. A thematic analysis, to explore the transcribed text from the focus groups as well as from the written mail responses, was conducted by means of Nvivo, a program for qualitative data analysis. Results showed three main themes expressing reasons for participation: participation as a last resort, as an activity of hope, and as a way to take responsibility for the development of a cure that will benefit future generations. The responses relating to the question about affected individuals' view of exerting influence resulted in two themes. The first theme was having a voice when researchers design experiments, which may give a sense of receiving respect. The second was that influence is an essential part of the information process before agreeing to take part in an experimental trail.
\end{abstract}




\section{Keywords}

Huntington's Disease, Participation in Clinical Trials, Influence, Focus Groups, Coping

\section{Introduction}

Years later, I asked my Dad just what he said that afternoon. "I told you your mother had Huntington's chorea," he says, "that it was a progressive, degenerative, neurological illness, that it often caused madness, that it was always fatal, and that both you and your sister each have a fifty-fifty chance of inheriting the illness yourselves. You know what you both said?" he asks. "Fifty-fifty? That's not so bad.' That took a terrific load off my mind." "But of course it wasn't true," I tell him. "I was scared to death" [1].

In her autobiography, Mapping Fate: A Memoir of Family, Risk, and Genetic Research, long since a classic and an important source of information for both scientists and affected individuals, Alice Wexler describes the moment when her father told her and her sister that the family was suffering from Huntington's disease. Although she knew for years that her mother was seriously ill, as other relatives were, it was impossible to digest the extent of her father's information. She needed several years to be able to talk to him about it again.

Huntington's disease (HD) is a genetic neurological brain disorder in which affected individuals lose their ability to walk, talk, think, and reason. The disease was previously known as chorea, a term that is derived from the ancient Greek word for dance and alludes to the afflicted individual's movements that are not rhythmic, but appear to flow from one muscle to the next. In Western countries, it is estimated that HD affects about five to seven people per $100,000{ }^{1}$ Although relatively rare, the disease has fatal consequences. It is genetically inherited with a $50 \%$ risk of being affected. There is no cure for this disease and it leads to an early death. Worldwide, scientists are trying to develop therapeutic methods that could cure the disease, including new methods of molecular gene therapy [2]-[4].

Developing treatments and medicines usually means that tests are done at the cellular level and in animal models. Thereafter, the method is ready for clinical trials with humans. The fact that medical tests and experimental therapies, almost regardless of what diseases the tests concern, must be translated to clinical settings in order to bring the biomedical scientific progress to the patients involves a number of complex issues [5] [6]. These relate to questions ranging from research design, safety, and therapeutic effectiveness to psychosocial aspects [7] [8]. Furthermore, the development of medicine creates a field of tension between hopes of successful cures and the real opportunities that exist for achieving such therapies [9] [10]. Scholars of socio-culture and ethics ${ }^{1}$ http://www.ninds.nih.gov/disorders/huntington/huntington.htm 
suggest that this tension between hope and actual medical opportunities highlights the importance of investigating patients' views and expectations of medical research. Equally important is to inform potential research subjects in a medical experiment what the research means and not least what their role might be [11].

As discussed by many scholars, it is valuable to include laypeople, such as those medically affected [12] [13]. However, even though the literature advocates an upstream engagement where laypeople are involved and given influence early in the research process, there is a lack of studies that are empirically grounded in the potential research subjects' experiences [14]. There is little knowledge regarding, among other things, HD-affected individuals' own approach to possible participation in an experimental study and their views on influence [15]. At Lund University, medical research on HD is now about to step from animal models to trials with humans. ${ }^{2}$ The project is special in its design because it involves both medical studies and socio-cultural and psychological research. The aim of this collaboration is to explore and meet the many challenges that experimental trials with HD patients give rise to. An important task is to fill the knowledge gap that exists regarding affected people's perceptions of what it means to them to participate in clinical trials as well as their thoughts on the possibilities of exerting influence in medical research.

\section{Aim of the Study}

The present study focuses on the socio-cultural and psychological aspects of experiments regarding HD. The objective is twofold: firstly, to gather knowledge about HDaffected individuals' views of participation in experimental trials as well as why they consider participation; secondly, to gather knowledge about HD-affected individuals' views of exerting influence in medical research about $\mathrm{HD}$.

\section{Method}

\subsection{Participants}

A total of 16 ( 9 women and 7 men) participants took part in focus group meetings or filled in a questionnaire. The questionnaires were filled in by those who were not able to attend the meetings. The mean age of all participants was $51.8(\mathrm{SD}=12.2)$. The youngest participant was 30 and the oldest was 69 years old. The participants who took part in the focus group interviews were affected by Huntington's disease in this way: Two participants were diagnosed with the disease, one was tested positive for the mutated gene, one was at risk for carrying the mutated gene, four were relatives, and one did not declare in what way s/he was affected. The participants who responded by questionnaires were affected by Huntington's disease in this way: One participant was diagnosed with the disease, two were tested positive for mutated gene, one was at risk for the disease, two were relatives and one did not declare how he/she was affected.

${ }^{2}$ Project: RNA editering för behandling av Huntingtons sjukdom. RNA editing for the treatment of Huntington's disease (Project number: K2012-99X-22330-01-5, ID: C0585401, the Swedish Research Council). 


\subsection{Materials}

In order to investigate the viewpoints of individuals affected by Huntington's disease (patients, carriers of the mutated gene or relatives) on the issues of influence and participation in medical research, we performed focus groups and sent questionnaires by letters.

The first questions that were explored in the focus groups and questionnaires were participants' views regarding taking part in a medical study that had not previously been tested on humans. We asked about how the affected individuals viewed the prospect of participating in an experimental medical study on gene therapy that involved patients who were affected by Huntington's disease, as well as why they could consider participating in such an experimental study. In addition we posed a question about their views on having an influence in medical research about HD.

\subsection{Procedure}

We conducted two focus groups with a total of nine participants. The focus groups lasted between two and three hours and were conducted in Gothenburg and Lund. Since several participants who lived far from these two cities wanted to participate, some of these people received the questions from the focus groups by mail and in total seven people responded by mail. Participants in the focus groups were recruited through the national association for Huntington's disease and the neurological clinic at Lund University Hospital. Letters with information about the study along with an invitation to participate in the focus groups were sent to affected individuals through these two channels. Those who wanted to participate in the focus groups contacted the research group in order to give notice of interest.

\subsection{Ethical Considerations and Ethical Approval}

There are no medical risks in the study. However, participants in the focus group study may experience discomfort about such detailed reporting on their disease problems, which are incurable. It appears that the positive effects outweigh the negative ones since the participants see the focus groups as a long-awaited way to vent difficult experiences with others in the same situation. The Ethics Review Board in Lund approved the study on 11 December $2013^{3}$ (Dnr 2013/794).

\subsection{Strategy of Analysis}

A thematic analysis, to explore the transcribed text from the focus groups as well as from the written mail responses, was conducted [16]. The analyses were performed by means of NVivo, a software program for qualitative data analysis, to help organize the material. The program facilitates analysis of texts since it can be used to create an elaborate index system and generate categories of themes. Different expressions concerning the participants' views of taking part in an experimental medical study and of how to influence when taking part in such a study were identified and coded. When all 
the transcripts and texts were coded, the contents of the different expressions were analysed, looking for patterns of variation in the text, and clustered into themes.

\section{Results}

The results show that the majority were in favour of participation and also that the majority desired to have influence on HD research. The stated reasons for participation resulted in three main themes. These themes are: participation is a last resort, participation is an activity of hope, and participation is a responsibility. The responses relating to the question about affected individuals' view of exerting influence resulted in two themes. These themes are: To have a voice and get respect, and individual experiences are essential for the information process prior to participation in an experimental clinical trial.

\subsection{Views of Participation}

\subsubsection{Participation Is a Last Resort}

The participants in our study expressed a great willingness to take part in experimental medical studies. There was no clear and single reason for the importance of participating in clinical trials. However, a frequent argument was that the lack of existing treatments for the disease created vulnerability with no real choices. Many participants emphasised that this life situation offered no other possibilities for improving their situation than to participate in clinical trials. They also emphasised that, on the basis of their lived experience with HD they were fully capable of making well-considered choices in relation to participation in clinical trials.

And I think that these are rather well-considered choices, because they [affected and relatives of affected] have lived with the disease and with diseased relatives, and have seen the whole phase, this progressive degradation, that's how it is. It's like I just said, our children they have seen their grandfather, you know... I don't want to experience something like that... no way! I don't to want live like that (with a progressive degradation).

One of the participants stressed that there was a need for "more invitations, I want to participate". Another one explained the need for invitations and participation as follows:

Huntington's is the worst disease that you could be affected by. The progression of the disease means a degeneration of the physical and mental abilities.

Yet another participant formulated it like this:

Had it been some other disease, where you could say that there is some medication that could alleviate then it would have been different, but with this disease, there's nothing and therefore you take the chances there are.

The extensive will to participate in medical research was related to the view of the clinical trials as a last resort and to a hope for treatments of the disease. However, the positive attitude also had elements of uncertainty concerning the experiments and the expected results. The respondents were aware that it was impossible to predict the ef- 
fectiveness and potential side effects that might result from taking part in the study as research subjects. Although the respondents were aware of uncertainties surrounding experimental therapeutic interventions that had not been tested on humans before, they did not consider participation in medical research as involving particular risks, but that non-participation might entail a risk because any medical advances would not benefit themselves. Two HD-affected people discussed the risk perspectives as follows:

P1: There's risk whatever way.

$P 2$ : There's more risk in not participating.

P1: It's not like you're going from something that doesn't entail risks to something that is filled with risks... It's not... you're always in some sort of zone that contains risks.

Some participants explained that the risk perspective would be different if experimental research were conducted on individuals who were not ill or had a disease for which effective medication existed. If this were the case, it would be wise to discuss risks. But since HD patients are seriously ill and there is no effective medication that halts the progression of the disease, experimental research on such persons is different in terms of risks.

I think that it's really a risk when you'll do this [a gene therapeutic intervention] at a stage when the person still can live an active and, so to speak, a dignified life. But if the disease has gone to those stages when the individuals are really sick, then I feel that it's less risk, then you' re more inclined to take chances.

Some participants argued that even if the research did not yield novel treatments, or they would not be eligible for such treatments, participation as a research subject would nevertheless make it possible enable to gather useful information that otherwise would be unknown. A pragmatic attitude towards uncertainties that in many cases are intrinsic features of experimental medical research was thus evident among the affected individuals. This pragmatic attitude also was evident in statements made about contemporary research being more reliable and safe than before.

It's more safe and secure nowadays than earlier in relation to research. That's how I think about it. You have to be... it's safer nowadays to participate in experimental trials.

The participants in our study argued that they had nothing to lose as a participant in medical research on the disease. The participation in the clinical trials was a last resort.

\subsubsection{Participation Is an Activity of Hope}

The respondents described a situation where they experienced powerlessness while they longed for self-control. A common statement was that they were not offered many options to change their life situation, thus participation in medical research could be not only a way to improve their chances for a slightly better life but also a strategy to counteract involuntary passivity and inactivity. This longing for activity was expressed by one participant in the following words:

I can feel some sort of trust... that something is happening, you get information and you see that a new line of approach is coming, so to speak, that actually confirms that something is happening [...] Then, sure... that's just words, it's text... it's not some- 
thing tangible [...] But even though, I can be happy because then I know that somebody is thinking about us... Look there, now something has happened, and look there [...] all of a sudden the world becomes much bigger [...] and you know, that gives me hope.

Apart from giving hope, news about research gives those who are affected by the disease a feeling of ongoing activity that compensates for their experience of passivity. This was particularly evident when participants explained the feeling of receiving information that treatment is within reach of medical science. Despite the current situation of no available cure or treatment that halts the progression of the disease, some of the people with HD still hoped for a cure, and explained that it was the idea of the progress of research that kept them alive.

In our family, it is so... intense. All my siblings have it and I have seen my grandmother and my grandmother's sister, she was detained for five months... New medicines, that's what we hope for, it is about hope and life.

There were no references to specific treatments or any particular line of research on $\mathrm{HD}$, but rather to a general idea of hope that was generated by news about research activities. Moreover, some participants were convinced that HD, because of scientific progress, would eventually be eradicated, and they drew parallels to polio, which has been eradicated in many parts of the developed world by effective vaccines.

So, it $s$ a good thing if there's something coming out now because it's a better situation research-wise... with computers, scanning, and so on... than how it used to be earlier.

Even if information about research progress were of great importance, some of the participants mentioned that during 30 - 40 years of research on the disease "nothing had actually happened" that radically changed the situation:

I think that's a bit hard, because it's on two levels. On one hand, you can see that something is happening; you can see that Karolinska [a research institute in Stockholm] is doing something, and so on. But, on the other hand... [sighs]... if I should be more practical, I would like to see... SOMETHING! I would like to see possibilities that enable me to act... And, that's good, that they' re making progress at Karolinska, and in Lund, but $1 \mathrm{~m}$ interested in those cases where there can be an early form of medication, where there's something that I can do... an early form of medication that you can try.

The steady stream of news and information about research that did not lead to any concrete results in the form of an effective treatment gave rise to feelings of both resignation and frustration. An ambivalent opinion about research could thus be discerned, where the affected individuals on the one hand sensed that a lot of research on HD was being conducted all around the world, while on the other hand they felt that nothing had actually happened.

The desire to be active to counter the disease became evident not only in the desire to participate in the clinical experiments, but also in the desire to seek out treatments without approved clinical trials. This became striking in a discussion on the purchase of stem cell treatments. Although treatments with stem cells were not scientifically proven and therefore not available in Sweden, all participants except one said that if they had 
the money and the opportunity turned up, they would travel abroad and buy stem cell treatments in order to be treated or cured of HD. The participant who was strongly against this idea argued that it was unfair to be forced to pay in order to get treated. The others agreed on this, but nevertheless emphasised that if they had the money, they probably would still go. The discussion on unproven and illegal stem cell treatment became emotional and harsh as it triggered a clash between the idea of equal rights to treatment that the national health care system in Sweden rests on, and the precarious situation of HD-affected as regards possibilities for treatment.

\subsubsection{Participation Is a Responsibility}

Although the respondents in general expressed trust and faith in medical research, they were aware that researchers were not able to develop novel treatments for HD on their own. At certain stages of their research, they will depend upon human research subjects who are willing to participate in clinical trials of novel treatments. The affected individuals who took part in the study frequently spoke of themselves as being united with medical researchers in the battle against HD. They talked about themselves as important actors in the research, and that they should help the researchers.

It is obvious that there may be risks, but on the other hand, someone has to be the guinea pig. And I ll be happy to be the guinea pig, it doesn't matter...

The importance of taking part in pushing medical research forward also entailed a more collective understanding that was directed towards other affected individuals, and towards patients affected in the future. A respondent explained why it was important to take part, despite the uncertainties that came with participation as a research subject:

I want do to everything. Partly for selfish reasons, I can help my family, and partly because I want to do something for all of those that are affected. It's about today and the future.

Another individual likewise discussed participation in terms of something that would help future generations.

We do this for our children and grandchildren. We do it for the future!

The respondents said that participating in medical research was a way to enhance the individual capability to tackle the devastating effects of the disease, but also to take responsibility to stop the disease from affecting further generations, as formulated by an HD-affected individual with children:

I think that all research is good, would love to be part of such a study in order to help others, for example my children.

The idea of having opportunities as well responsibilities to act in relation to the disease was evident when the affected individuals in the focus groups talked about participation as a way to put an end to the disease.

\subsection{Views of Participants' Influence in Medical Research about HD}

\subsubsection{To Have a Voice and Get Respect}

The participants in our study agreed on the importance of having influence over the research. There was no common definition of the concept of influence or what it would 
mean. However, a recurring theme was that influence meant having "a voice and something to say" and being respected as an individual. One of the participants in our study expressed it like this:

I want to have influence on the treatment, but above all get respect and to be listened to as a patient in terms of medication and treatment.

Several of the participants complained about a lack of patient influence, and some of them considered themselves to have been disrespectfully treated by the health care. A middle-aged man said:

My now quite adult daughter got a lot of medications, but she didn't feel good at all from the drugs she received. She would have needed more than sedatives and such stuff... it's all for her anxiety for the disease. I know that her problem was and is her anxiety about being hit by HD... just as it was for me [the father]. But no one listened to her... she was a minor then, and so she had nothing to say. And we didn't know.

Other participants argued that in order to make demands, to have something to say, it was necessary to have access to knowledge, for example by having insight into their own medical records. Therefore, they urged the need for transparency and the importance of getting detailed and correct information from doctors.

For me patient influence means that it is important to be informed about treatment options and about the contents of my medical records. And, that you can turn to an ombudsman about becoming mistreated.

Some participants in our study stated that they should have opportunities to influence what medical research would be conducted in Sweden. They also pointed out the importance of patient organisations as driving forces.

It goes without saying that one should have influence as a patient, and I really want to have more influence on what is going on in HD research. Therefore, it is important to be connected to a patient organisation that can influence the attitudes of society to alleviate the stigma surrounding $H D$.

Particularly important to influence, they pointed out, was that the Swedish government not only supported research on common diseases represented by strong patient associations, but also rare diseases such as HD.

I would like to influence, in order to get a good treatment with many treatment options. I would like to fund more research, for example, with taxes [...] Cancer research gets lots of grants-we want HD scientists to get the money to develop the research. But we who suffer from $H D$ are not so many.

\subsubsection{Individuals' Experiences Are Essential for the Information Process Prior to Participation in an Experimental Clinical Trail}

Even though a recurring theme among respondents was that they should have opportunities to exert influence, for example through their patient organisation, they agreed that strict medical issues and decisions were not relevant to them since "going in and turning off something, or changing a gene and so on, I feel that it sort of is not my area".

None of them considered that they had the kind of expertise that would legitimate 
them to interfere with medical issues. Instead, they wanted to contribute with personal experience of being HD-affected and share this "unique and individual-based knowledge" with researchers who design clinical trials. They argued that their own lived experience as HD-affected was valuable knowledge for the researchers. Medical researcher would need such knowledge to understand what potential research subjects should be informed about and how to disseminate the information.

We can help with certain aspects. In some way... our expertise is [unique]... you know.

The participants in our study made clear the importance of and need for information about what it meant to take part in a clinical experiment. In general, it was obvious that a written document was not viewed as adequate for the purpose of receiving information about medical research and experiments. Some participants considered written information, which is part of the process of signing informed consent and which must precede all clinical trials, as something that complicated the understanding of what the project involved. The signing of a document was thus not viewed as particularly important, but rather something they wanted to get over with quickly. Some participants viewed the document as a formal and meaningless routine. This aspect of the informed consent as a mere formality was expressed like this:

It's more or less a formal procedure, yes, and nothing that has any great implication for me. But I do think that it could take on greater importance if the consent form conveyed a more positive experience about the participation.

The respondent did not specify the nature of such a "positive experience" or how it could be practised or realised. Some of them also indicated that the information would show both positive and negative sides, to avoid "persuasion or indirect promises" to participate. Yet ideas were expressed by several, as well as called for a close and open dialogue between potential research subjects, medical doctors and scientists. The aim of the dialogues should be to give information adapted to individual requirements and make it possible for potential participants to pose questions. The participants in our study also felt that it would be possible for them, through dialogue, to express their views and opinions and thus achieve an influence. The dialogue was described as a reciprocal communication through which the affected individuals wished to establish a trusting relationship with the researchers. Another purpose of such a dialogue was to make them comfortable enough to change their mind at any time during their participation and leave the project. A discussion between some of the participants went as follows:

P3: It's what was said before, what I think is very important, and this is on an individual basis, of course. Maybe there are people who don't want this, you know. I want to have the feeling that $P \mathrm{~m}$ safe, and when it comes to clinical trials, that they [medical researchers] show their cards, that they say like "this is how much we have done, and these are the results that we have", so that I can take an individual decision, you know.

P4: I feel that's intrinsic to the trust [for the scientists]:

P5: Absolutely, absolutely 
P3: As said before, you really must hope that they really... as said, show their cards, so that everyone can see and understand...

Participants in our study considered that the overall objective of a dialogue would be to provide opportunities for them to make informed decisions about participation as a research subject in clinical trials. What form this kind of dialogue could take was also discussed among them. Some advocated a mix of group discussions and individual conversations between patients and researchers. The main rationale for attending group discussions was considered to be the prospect of an extended contact with the researchers and an expectation that this environment would provide opportunities for discussion about what was going to happen in the medical project. Other participants pointed out the need to reflect on and to discuss participation in experimental trials, not with doctors and researchers only, but with other affected individuals. Some participants requested such discussions to serve as psychological ventilation where people in the same situation could inspire and support each other.

It would be very useful to have a discussion, like we have right now, in this group, before you participate [in clinical trials]. Because then you have gained additional experience and knowledge, I think. What do others think or do I have a different opinion and so on.

The request for information and a dialogue with fellow patients and with medical HD experts was seen as important for both giving and receiving information. In such a reciprocal process, they would be able to exert influence, as it was described rather vaguely-not on the experimental study itself, but regarding how information about the experiment would be conveyed to research subjects.

\section{Discussion}

The present study aims at exploring HD-affected individuals' perceptions of what it means to participate in experimental clinical trials that had not previously been tested on humans, as well as their thoughts about the possibilities of exerting influence in medical research. For this purpose, we used focus group discussions and questionnaires by mail with HD-affected individuals.

1) The results revealed that the majority were in favour of participation. This positive attitude, and the trust expressed by several of the participants in medical research, is consistent with other findings regarding how seriously ill individuals relate to unproven treatments [17]. Previous studies, including the attitude of Parkinson's and MS patients to clinical experiments, found a willingness to seek out new treatments but also doubt because of potential risks [18] [19]. It is worth noting that the participants in our current study did not describe the clinical experiments in terms of risk but as opportunities, as a chance. HD is genetically inherited with a $50 \%$ risk of being affected, and those carrying the mutated gene are confronted with a neurological degenerative disease that not only breaks down the body, but also affects them with major personality changes. The willingness of the HD-affected people to participate should be seen in the light of this highly problematic medical and social situation that is already characterised by ex- 
tensive risks [20]-[22]. The results show, further, that the positive views on participation did not primarily emanate from ideas about patient rights, as discussed by scholars examining participation in terms of democratic implications and as a way to counteract the dominance of experts [9] [23]-[25]. Although we asked questions about patient rights, the participants in our study did not stress these democratic aspects, but instead spoke of participation as a way to cope with a difficult and precarious situation. The way that HD-affected people seek different strategies to cope with a difficult situation is also documented [22]. An interview study found a variety of coping strategies expressed by HD-affected individuals [22]. The strategies included seeking information, seeking possible solutions such as changing diet and attempts to regulate emotions. Previous research on psychological well-being among Huntington patients shows a linkage between coping and psychological well-being [7].

Thus, besides being a last resort to find a cure, being part of an experimental clinical trial is a way to take action, i.e. a strategy to counteract feelings of being passive and helpless, as well as to achieve a sense of empowerment. It should be emphasised that precisely the certainty that HD-affected people experience are, as they put it, "doomed" to destruction appears to give them a willingness to help others. Thus, the sense of being empowered includes not only the individuals who are affected by the disease, but also future generations. Participation in medical research in order to find effective treatments seems to bear hope also for future generations of individuals who are at risk of inheriting the mutated gene.

2) The thematic analysis showed that several of the participants in the present study desired not only to participate, but also to have influence on HD research. The results are interesting in relation to earlier and contemporary discussions in socio-cultural studies and psychological investigations. Biomedical research has for a fairly long time interacted with laypeople. This interaction is particularly common among researchers and patient organisations [15] [17] [26]-[28]. A crucial factor for the commitment exerted by various patient organisations is their awareness and knowledge of medical conditions. In some cases upstream involvement may have an impact in not only conveying affected individuals' experiences, but also for the content and design of research projects [29]-[31]. Further, situations may arise where patient organisations or individual patients can influence the early phases of the research process. This is clearly observable in HD research. Commitment from affected individuals was essential to gather and initiate research that could locate the mutated gene that causes the disease. Today HD patient organisations have a key role in the funding of research on the disease [31]. Our findings are consistent with such observations regarding the perception of patient organisations as a driving force [1] [32]. The respondents in our study suggested that the patient organisations are key players in calling for more research on HD to be funded by taxes. It is noteworthy, however, that the majority of the comments in our study regarding the importance of influence did not primarily concern the patient organisations having possibilities to direct the HD research. Instead they emphasised the need for information and that their own experience would be respected as a basis 
for designing information about the clinical trials. There was a clear desire to influence the process of information given to the participants before participation in an experimental clinical trial, through a mutual exchange of information, i.e. a dialogue with the medical researchers. Such a reciprocal process was seen as a way for potential research subjects to reach an individual and independent decision about participation.

The results can provide information for medical researchers on how to communicate with patients when taking part in clinical experiments. The study suggests that it is important to take into account potential research subjects' needs for influence on how information about the experiments can be conveyed. The study may thus provide valuable information to researchers regarding designing applications for the ethical review boards. The study further highlights the importance of recognising HD-affected individuals and other groups with severe diseases as especially vulnerable when designing applications for ethical vetting. One reason is their tendencies to express a will to participate as a way to cope with a difficult and precarious situation. We therefore suggest that the sections about people who temporarily or permanently are not capable of personally giving their informed consent also include $\mathrm{HD}$-affected and other groups with severe diseases. ${ }^{4}$

\subsection{Limitations and Future Research}

Some limitations of the present study should be mentioned. In focus groups time can be lost since group discussions can be difficult to control. Irrelevant topics can be dwelled upon for too long. Respondents can feel peer pressure to give the same answers as other participants. Responses can also be affected by the moderator's skill in phrasing questions.

The study consists of few participants, which is due to the number of HD patients in Sweden. Since the study is only carried out in Sweden the results cannot be generalised to other countries. Thus, more studies need to be implemented in other national contexts as well.

\subsection{Conclusion}

In the present study, the aim was to investigate the viewpoints of HD-affected regarding participation and exerting influence in taking part in experimental medical studies. Thematic analysis showed three main themes expressing reasons for participation: participation as a last resort, as an activity of hope, and as a way to take responsibility for the development of a cure that will benefit future generations. Responses relating to the question about affected individuals' view of exerting influence resulted in two themes. The first theme was having a voice when researchers design experiments, which may give a sense of receiving respect. The second was that influence is an essential part of the information process before agreeing to take part in an experimental trail. The re${ }^{4}$ See for example current Swedish application form for ethical vetting. The application form is updated (according to VRFS 2012:1) and valid from 27 March 2012. http://www.epn.se/en/start/ (accessed 11 August 2016) 3:1 How are participants in the research chosen. 
sults can provide information for medical researchers on how to communicate with patients when taking part in clinical experiments. Based on the findings of this study, future research should consider conducting studies in other countries.

\section{Acknowledgements}

Thanks to Niclas Hagen, cultural scientist, for contributing to the data collection, and the medical scientists Åsa Petersen and Deniz Kirik for project coordination. We thank the participants in our study for sharing their stories with us. We also thank representatives of the medical genetics clinic and the local branch of the HD patient organisation for their help with recruitment. In addition we thank the reviewers for their valuable comments, and Stellenbosch Institute for Advanced Study Wallenberg Centre, 10 Marais Street, Stellenbosch 7600, South Africa. The project is financed by VR (dnr C0585401) and RJ (dnr SAB15-03021).

\section{References}

[1] Wexler, A. (1995) Mapping Fate: A Memoir of Family, Risk, and Genetic Research. Random House, New York.

[2] Petersén, Å. and Kirik, D. (2016) Twisting Mice Move the Dystonia Field Forward. Journal of Clinical Investigation., 124, 2848-2850. http://dx.doi.org/10.1172/JCI76624

[3] Björklund, A., Björklund, T. and Kirik, D. (2009) Gene Therapy for Dopamine Replacement in Parkinson's Disease. Science Translational Medicine, 1, 1-5. http://dx.doi.org/10.1126/scitranslmed.3000350

[4] Bloch, J., et al. (2004) Neuroprotective Gene Therapy for Huntington's Disease, Using Polymer-Encapsulated Cells Engineered to Secrete Human Ciliary Neurotrophic Factor: Results of a Phase I Study. Human Gene Therapy, 15, 968-975. http://dx.doi.org/10.1089/hum.2004.15.968

[5] Konrad, M. (2005) Narrating the New Predictive Genetics. Cambridge University Press, Cambridge. http://dx.doi.org/10.1017/CBO9780511584183

[6] Gottweis, H. and Petersen, A. (2008) Biobanks-Governance in Comparative Perspective. Routledge, Abingdon.

[7] Kaptein, A.A., et al. (2006) Illness Perceptions and Coping Explain Well-Being in Patients with Huntington's Disease. Psychology and Health, 21, 431-446. http://dx.doi.org/10.1080/14768320500456947

[8] Parkenham, K.I., Goodwin, V.I. and Macmillan, C.J. (2004) Adaptation to Being At-Risk for Huntington's Disease and the Availability of Genetic Testing: Application of a Stress and Coping Model. Psychology, Health and Medicine, 9, 380-318. http://dx.doi.org/10.1080/13548500410001721936

[9] Brown, N. (2003) Hope against Hype-Accountability in Biopasts, Presents and Futures. Science Studies, 16, 3-21.

[10] Franklin, Geesink, I. and Prainsack, B. (2008) Stem Cell Stories 1998-2008. Special Issue of Science as Culture, 17, 1-11.

[11] Rose, N. (2007) The Politics of Life Itself. Princeton University Press, Princeton. http://dx.doi.org/10.1515/9781400827503

[12] Hedlund, M. (2007) Demokratiska Genvägar: Expertinflytandei den Svenska Lagstiftning- 
sprocessenom Medicinsk Genteknik (Democratic Shortcuts: Expert Influence in the Swedish Legislative Process Concerning Medical Gene Technology). Lund Political Studies, Lund University.

[13] Hilgartner, S. (1990) The Dominant View of Popularization: Conceptual Problems, Political Uses. Social Studies of Science, 20, 519-539. http://dx.doi.org/10.1177/030631290020003006

[14] Novas, C. (2007) Genetic Advocacy Groups, Science and Biovalue: Creating Political Economies of Hope. In: Atkinson, P., Glasner, P. and Greenslade, H., Eds., New Genetics, New Identities, Routledge, Abingdon, 11-27.

[15] Hagen, N., et al. (2013) Genetics and Democracy-What's the Issue? Journal of Community Genetics, 4, 181-188. http://dx.doi.org/10.1007/s12687-012-0109-x

[16] Parker, I. (2005) Qualitative Psychology: Introducing Radical Research. Open University Press, Maidenhead.

[17] Lundin, S. (2002) Creating Identity with Biotechnology: The Xenotransplanted Body as the Norm. Public Understanding of Science, 11, 333-345. http://dx.doi.org/10.1088/0963-6625/11/4/302

[18] Idvall, M., Wiszmeg, A. and Lundin, S. (2013) Focus Group Conversations on Clinical Possibilities and Risks within Parkinson Disease: A Swedish Case Study. Department of Arts and Cultural Sciences, Lund University, Lund. https://lucris.lub.lu.se/ws/files/5849693/4360032.pdf

[19] Sjödahl Hammarlund, C., Nilsson, M.H., Idvall, M., Rosas, S.R. and Hagell, P. (2014) Conceptualizing and Prioritizing Clinical Trial Outcomes from the Perspectives of People with Parkinson's Disease vs. Health Care Professionals: A Concept Mapping Study. Quality of Life Research, 23, 1687-1700. http://dx.doi.org/10.1007/s11136-013-0614-3

[20] Uhlmann, W.R. (2010) Book Review, The Woman Who Walked into the Sea: Huntington's and the Making of a Genetic Disease. American Journal of Human Genetics, 86, 830-831. http://dx.doi.org/10.1016/j.ajhg.2010.05.007

[21] Williams, J.K., et al. (2010) In Their Own Words: Reports of Stigma and Genetic Discrimination by People at Risk for Huntington Disease in the International RESPOND-HD Study. American Journal of Medical Genetics Part B: Neuropsychiatric Genetics, 153B, 1150-1159. http://dx.doi.org/10.1002/ajmg.b.31080

[22] Etchegary, H. (2009) Coping with Genetic Risk: Living with Huntington Disease (HD). Current Psychology, 28, 284-301. http://dx.doi.org/10.1007/s12144-009-9061-2

[23] Fischer, F. (2009) Democracy \& Expertise: Reorienting Policy Inquiry. Oxford University Press, Oxford. http://dx.doi.org/10.1093/acprof:oso/9780199282838.001.0001

[24] Rogers, K. (2008) Participatory Democracy, Science and Technology. Palgrave-Macmillan, Basingstoke.

[25] Irwin, A. (1995) Citizen Science: A Study of People, Expertise and Sustainable Development. Routledge, London.

[26] Gibbon, S. and Novas, C. (2008) Biosocialities, Genetics and the Social Sciences: Making Biologies and Identities. Routledge, London.

[27] Hagen, N. (Unpublished) Genetics, Body, and Ambivalence.

[28] Nelis, A., de Vries, G. and Hagendijk, R. (2007) Patients as Public in Ethics Debates: Interpreting the Role of Patients' Organisations in Democracy. In: Atkinson, P., Glasner, P. and Greenslade, H., Eds., New Genetics, New Identities, Routledge, London, 28-43.

[29] Silverman, C. (2008) Brains, Pedigrees, and Promises: Lessons from the Politics of Autism Genetics. In: Gibbon, S. and Novas, C., Eds., Biosocialities, Genetics and the Social Sciences, 
Routledge, Abingdon, 38-55.

[30] Callon, M. and Raberhariosa, V. (2002) The Involvement of Patients' Associations in Research. International Social Science Journal, 54, 57-63.

http://dx.doi.org/10.1111/1468-2451.00359

[31] Epstein, S. (1996) Impure Science: AIDS, Activism, and the Politics of Knowledge. University of California Press, Berkeley.

[32] Hagen, N. (2013) Modern Genes: Body, Rationality and Ambivalence. Lund Studies in Arts and Cultural Sciences, Lund.

\section{Submit or recommend next manuscript to SCIRP and we will provide best service} for you:

Accepting pre-submission inquiries through Email, Facebook, LinkedIn, Twitter, etc.

A wide selection of journals (inclusive of 9 subjects, more than 200 journals)

Providing 24-hour high-quality service

User-friendly online submission system

Fair and swift peer-review system

Efficient typesetting and proofreading procedure

Display of the result of downloads and visits, as well as the number of cited articles

Maximum dissemination of your research work

Submit your manuscript at: http://papersubmission.scirp.org/

Or contact ojmp@scirp.org 